\title{
Missing Study Animal
}

National Cancer Institute

\section{Source}

National Cancer Institute. Missing Study Animal. NCI Thesaurus. Code C96372.

An indication that the test system (animal) could not be found, in which case, its disposition was not known, and no postmortem data was available. 